\title{
Hemorheology and renal function during cardiopulmonary bypass in infants
}

Sven Dittrich, Max Priesemann, Thomas Fischer, Wolfgang Boettcher, Christian Müller, ${ }^{1}$ Ingo Dähnert, Peter Ewert, Vladimir Alexi-Meskishvili, Roland Hetzer, Peter E. Lange

Deutsches Herzzentrum Berlin; ${ }^{1}$ Department of Clinical Chemistry and Biochemistry, Charité Med ical Center, Virchow Hospital, Humbold t University, Berlin, Germany

Abstract Backg round: Acute renal failure is an occasional complication after cardiopulmonary bypass in infants. Whereas it is well known that postoperative hemodynamics inflict acute renal failure, the influence of extracorporeal circulation on the kidney is less clear. Moreover, changes in blood viscosity occur during and after surgery, which may influence renal dysfunction. For this reason, we investigated the impact of blood viscosity on renal function during cardiopulmonary bypass. Methods: In 34 patients weighting less than $10 \mathrm{~kg}$, we performed repeated analysis of urine, blood, and plasma viscosity. Results: Polyuria and proteinuria that appeared during cardiopulmonary bypass indicated an elevated transglomerular filtration gradient, which recovered within 24 hours. The appearance of $\mathrm{N}$-acetyl- $\beta$-D-glucosaminidase in the urine, and elevated excretion of sodium, were additionally indicative of mild tubular damage. Elevation of blood viscosity during hypothermic perfusion showed a statistical correlation with proteinuria and $\mathrm{N}$-acetyl- $\beta$-D-glucosaminidaseuria. With hypothermia, the relation of blood viscosity to plasma viscosity became stronger, while the relation to the hematocrit decreased compared to normothermia. Conclusions: During cardiopulmonary bypass perfusion, the kidney can be stressed by proteinuria and mild tubular damage. Our data provide evidence that the kidneys can be protected by improved blood viscosity during cardioplegia, but this needs confirmation in a prospective interventional study.

Keywords: Congenital cardiac disease; infant cardiopulmonary bypass; blood viscosity; plasma viscosity

A CUTE RENAL FAILURE IS AN OCCASIONAL complication after cardiopulmonary bypass for correction of congenital cardiac malformations in infants. ${ }^{1,2}$ Despite postoperatively decreased cardio-circulatory function, which may cause acute renal failure, ${ }^{3-5}$ there is evidence that the alteration of renal function commences at the time of cardiopulmonary bypass. ${ }^{6,7}$ Renal function particularly depends upon blood flow. Recent experimental studies have discussed the involvement of blood viscosity and glomerular blood flow in the pathogenesis of chronic glomerular kidney disease produced by

Correspondence to: Dr Sven Dittrich, Universitätskinderklinik, Pädiatrische Kardiologie, Mathildenstrasse 1, D-79106, Freiburg, Germany. Tel: +49 761 270 4323; Fax: +49 761270 4468; E-mail: svsdittr@aol.com

Accepted for publication 28 February 2001 long-standing functional disorders. ${ }^{8,9}$ On the other hand, enhancement of the conditions underscoring viscosity is known to improve the properties of flow of blood in the kidney. ${ }^{10,11}$ The aim of this study was to investigate renal function in infants during surgery involving cardiopulmonary bypass with regard to hemorheology.

\section{Material and methods}

Selection of patients

We studied 34 consecutive infants weighing less than $10 \mathrm{~kg}$ who underwent correction of congenital cardiac malformations using cardioplegia and cardiopulmonary bypass (Table 1 ). Patients with renal diseases, as diagnosed by routine ultrasound, were excluded. During the period of study, 10 patients 
Table 1. Patients and bypass data.

\begin{tabular}{lcl}
\hline Age (month) & $3.1(0.2-16.3)$ & \\
Body weight $(\mathrm{kg})$ & $4.4(2.6-9.9)$ & \\
Bypass time (min) & $117(44-479)$ & \\
Aortic cross-clamping (min) & $59(17-121)$ & \\
Rectal body temperature during aortic cross-clamping $\left({ }^{\circ} \mathrm{C}\right)$ & $30.7(18.0-36.2)$ & \\
Mean blood flow during CPB $(\mathrm{ml} / \mathrm{min} / \mathrm{kg})$ & $189(115-277)$ & \\
Diagnoses & Patients no. & Type of surgery \\
Ventricular septal defect and /or atrial septal defect & 14 & Corrective \\
Atrioventricular septal defect & 6 & Corrective \\
Transposition of great arteries & 6 & Arterial switch \\
Tetralogy of Fallot & 2 & Corrective \\
Pulmonary atresia & 2 & Corrective \\
Bland-White-Garland syndrome & 2 & Corrective \\
Common arterial trunk & 1 & Corrective \\
Aortic stenosis & 1 & Commissurotomy \\
\hline
\end{tabular}

$\mathrm{n}=34$; Data are given as median (minimum-maximum); CPB: cardiopulmonary bypass

were excluded. Analysis of creatinine revealed levels below $0.8 \mathrm{mg} / \mathrm{dl}$ in the serum of all participating patients.

\section{Technique for card iopulmonary bypass}

After a bolus injection of heparin to achieve an activated clotting time of more than 480 seconds, nonpulsatile cardiopulmonary bypass was initiated with a microporous polypropylene membrane oxygenator that was selected according to the size of the patient and the requirements for flow (Safe Micro, Polystan, Vaerlose, Denmark; Lilliput D-701 or D-902, Dideco/Sorin, Mirandola, Italy) and an arterial filter (D736, pore size $40 \mu \mathrm{m}$, Dideco/Sorin). The extracorporeal circuit consisted of medical grade polyvinylchloride tubing except for silicone tubing in the raceway of the arterial non-pulsatile roller pump (Stöckert, Munich, Germany). The bypass circuit was primed with Jonosteril and pre-bypass filtrated (R3802 0.2 $\mu \mathrm{m}$ Pall Biomedical, Dreieich, Germany). The priming volume of $350-550 \mathrm{ml}$ consisted of isotonic electrolyte solution, which was partially replaced by $120 \mathrm{ml}$ of fresh frozen plasma in the newborn. We added $50 \mathrm{ml}$ of $20 \%$ albumin. One hundred to $300 \mathrm{ml}$ packed red blood cells to maintain a calculated hematocrit value over $15 \%$, and if necessary blood was buffered with $8.4 \%$ sodium bicarbonate. In one patient, we were able to use a bloodless prime. During bypass, the flow was routinely set at $31 / \mathrm{min} / \mathrm{m}^{2}$, temporarily reduced only with decreased venous return or at the request of the surgeon. Flow was controlled according to the venous oxyhemoglobin saturation measured on-line, and values of arterial blood gases. During the period of rewarming, higher flows were required to meet the increasing metabolic demands. Cooling was performed in the first 15-20 min of cardiopulmonary bypass (Table 1). Arterial tension of carbon dioxide was maintained throughout hypothermic cardiopulmonary bypass at $35-45 \mathrm{mmHg}$, uncorrected for temperature according to alpha-stat management. After cross-clamping the aorta, cardiac arrest was induced by injection of $50-100 \mathrm{ml}$ Cardioplegin- $\mathrm{N}^{\circledR}$ cardioplegic solution (Köhler, Alsbach-Hähnlein, Germany), followed by an infusion of Hamburg-Eppendorf ${ }^{\circledR}$ colloidal solution (Fresenius, Bad Homburg, Germany), with magnesium and procaine as cardioplegic agents. Colloid cardioplegic solution was then re-infused every 20-30 min. Systemic rewarming was initiated shortly before de-clamping the aorta. Median duration of bypass was $106 \mathrm{~min}$ (Table 1). Circulatory arrest was not used. After termination of cardiopulmonary bypass, modified ultrafiltration was performed uniformly in all patients according to the method introduced by Naik and Elliott. ${ }^{12}$ The aortic cannula was left in place, and blood from the aorta was passed through a hemoconcentrator (DHF 02, Dideco, Italy), the oxygenated blood being returned through a "Hot-Line" transfusion line (Smith Ind., Rockland, USA) to the right atrium to prevent a drop in temperature, particularly in neonates and small children. In the steady state period of cardiopulmonary bypass, after achieving full flow until the start of the weaning period, the mean flow for cardiopulmonary bypass was calculated from data recorded every $5 \mathrm{~min}$. Colloid osmotic pressure was measured with the Onkometer 923 (BMT, Germany).

\section{Anesthesia}

Patients were pre-medicated with midazolam, at a dose of $0.5 \mathrm{mg} \mathrm{kg}, 30$ minutes before the operation. 
Anesthesia was induced with midazolam at $0.2 \mathrm{mg} \mathrm{kg}$, sufentanyl at $1 \mu \mathrm{g} \mathrm{kg}$, and pancuronium at $1 \mathrm{mg} \mathrm{kg}$. After insertion of an endotracheal tube, and placement of arterial and central venous catheters, anesthesia was maintained by the continuous infusion of sufentanyl at $1-2 \mu \mathrm{g} k \mathrm{~kg}$ per hour, the use of an inhalational agent before the initiation of cardiopulmonary bypass, and an additional dose of midazolam at $30 \mathrm{mg} \mathrm{kg}$ during and after cardiopulmonary bypass. Prednisone, at $30 \mathrm{mg} \mathrm{kg}$, and mannitol at $0.5 \mathrm{~g} \mathrm{~kg}$, were given prior to cardiopulmonary bypass. During cooling and rewarming, all the patients received a continuous infusion of nitroprusside at $0.1-5 \mu \mathrm{g} \mathrm{kg}$ per minute.

\section{Periods of investigation}

Hemodynamic, renal and hemorheologic analyses were performed over five time periods:

- onset of general anesthesia - start of cardiopulmonary bypass,

- start of cardiopulmonary bypass - end of aortic cross-clamping,

- start of reperfusion - stop of cardiopulmonary bypass,

- four hours following the cardiopulmonary bypass, and

- 8-24 hours after the end of cardiopulmonary bypass.

\section{Evaluation of renal function}

Renal function was evaluated by analysis of protein and enzymes in urinary samples collected at specific times as previously described. ${ }^{13}$ Clearances of creatinine, and the excretion of sodium, were calculated with standard formulas. ${ }^{14}$

\section{Evaluation of hemorheology}

The hematocrit and hemoglobin were measured using a Coulter counter model Celldyn $3500^{\circledR}$ (Abbott, Illinois, USA). Viscosity was measured using a cone and plate viscometer (Wells-Brookfield, Massachusetts, USA) at shear rates of 225 per second, which represented the shear conditions in arterial vessels at temperatures that corresponded to the central body temperature during collection of blood samples as previously described. ${ }^{15}$

\section{Statistical analy sis}

Results are expressed as medians and ranges in the tables and for graphic presentation as mean plus and minus the standard error of the mean. For statistical analysis, we used the Mann-Whitney-U test for unpaired samples, the Wilcoxon-test for paired samples, and the Fisher exact test for comparison of numerical variables between groups. A Spearman's correlation coefficient of greater than 0.5 was interpreted as correlation between two different parameters, and $\mathrm{p}$ values less than 0.05 were considered to be statistically significant.

\section{Results}

\section{Analy sis of renal function}

When compared with the initial period of the operation, diuresis increased during the period of perfusion on cardiopulmonary bypass, and remained elevated for the first 24 hours after surgery (Fig. 1). The clearance of creatinine was elevated at the onset of cardiopulmonary bypass, and decreased below the preoperative values after cardiopulmonary bypass (Fig. 1). It remained lower for up to 24 hours. At the end of cardiopulmonary bypass, none of the patients was anuric, but three patients developed acute renal failure with oliganuria or anuria in the subsequent 24 hours. These patients were excluded from the subsequent postoperative analysis. Glomerular alteration, as indicated by elevated excretion of protein and albumin, was observed during the reperfusion period of cardiopulmonary bypass and in the early hours postoperatively. This disappeared within 24 hours in all patients (Fig. 1). Tubular alteration, as revealed by elevated urinary activity of the $\mathrm{N}$-acetyl- $\beta$-D-glucosaminidase, and elevated urinary excretion of sodium, became obvious during the reperfusion period of cardiopulmonary bypass, and in the first hours postoperatively. It normalized within 24 hours in all patients (Fig. 1).

\section{Hemorheology during card iopulmonary bypass}

When compared with the basal values, the hematocrit was diluted during cardiopulmonary bypass (Fig. 2). Plasma viscosity was elevated during hypothermic perfusion, but blood viscosity did not increase, and was slightly reduced during the period of reperfusi on (Fig. 2). The flow during hypothermic perfusion, and the period of reperfusion, were in a comparable range (Table 2).

\section{Factors influencing blood viscosity}

During normothermia, blood viscosity showed a statistical correlation with the hemoglobin and the hematocrit, while plasma viscosity was not correlated to the blood viscosity by statistical meanings (Table 3). In contrast, during hypothermic perfusion, the body temperature and the plasma viscosity were statistically correlated with the blood 

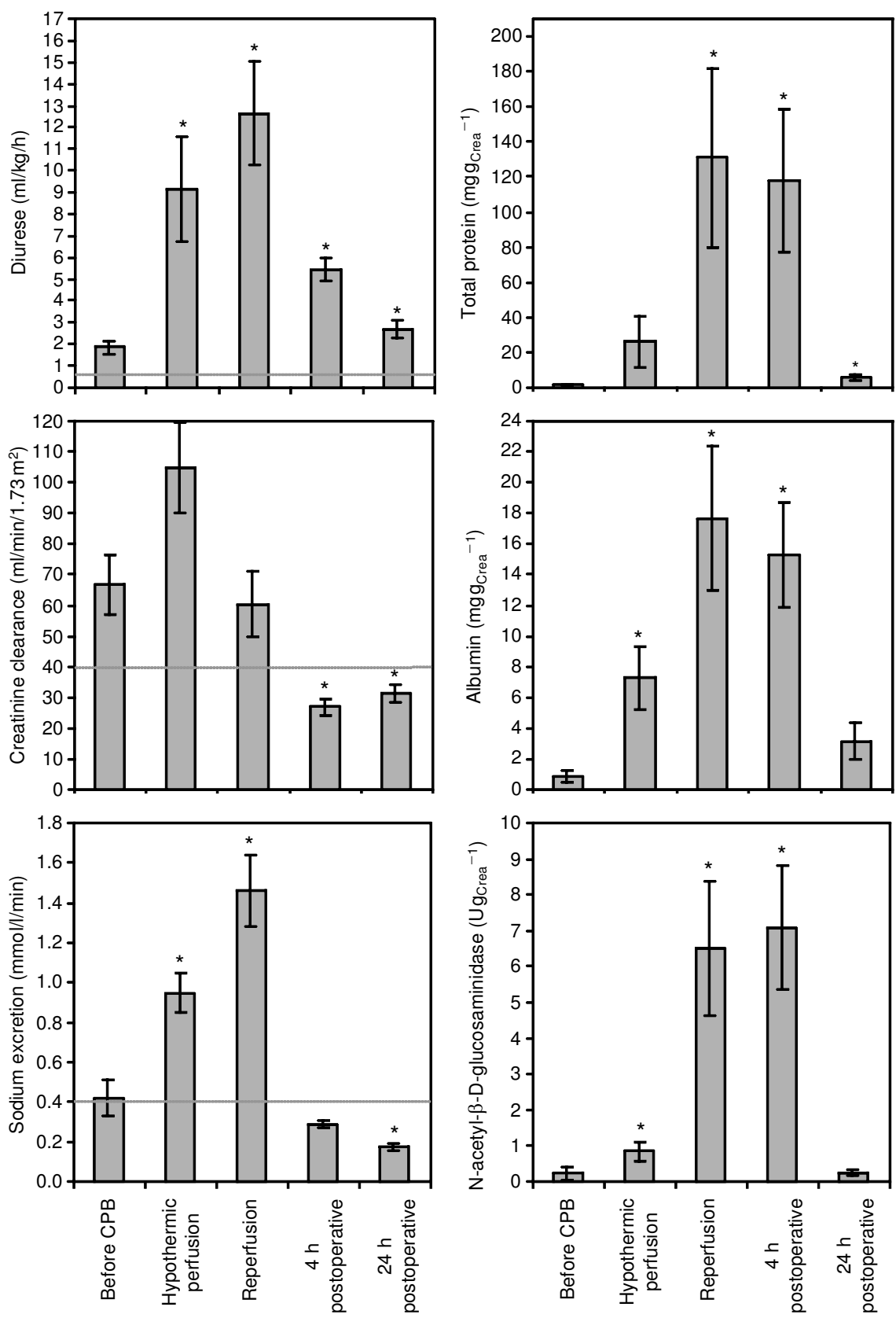

Figure 1.

Data are given as mean $\pm S E M$. ${ }^{*} p<0.05$ compared to first column. The dotted lines show the minimal reference values. The bars represent the analyses at the intra- and postoperative sample periods during cardiopulmonary bypass. While polyuria and elevated excretion of sodium appeared during extracorporeal perfusion (left sided diagrams), proteinuria and tubular impairment occur during the final period of cardiopulmonary bypass (right sided diag rams). The clearance of creatinine w as depressed after the operation.

viscosity, while hemoglobin and hematocrit were not (Table 3).

Comparison of renal function w ith demog raphic and card iopulmonary by pass data

Spearman's correlation analysis showed a relationship between central body temperature during hypothermic perfusion, and albuminuria during the period of reperfusion $(r=-0.615 ; p<0.0005)$. Blood viscosity during hypothermic perfusion was statistically related to albuminuria $(r=0.705 ; p<0.0005)$ and to urinary values of $\mathrm{N}$-acetyl- $\beta$-D-glucosaminidase $(\mathrm{r}=0.548 ; \mathrm{p}=0.001)$ during the period of reperfusion (Fig. 3).

\section{Comment}

This study focusses on two main topics. First, renal function was analyzed during the different periods of cardiopulmonary bypass and, secondly, on the basis of the rheological conditions. Our data demonstrate proteinuria and impairment of tubular cellular function during extracorporeal circulation and shortly after the period of cardiopulmonary bypass. The question is whether our findings indicate only 

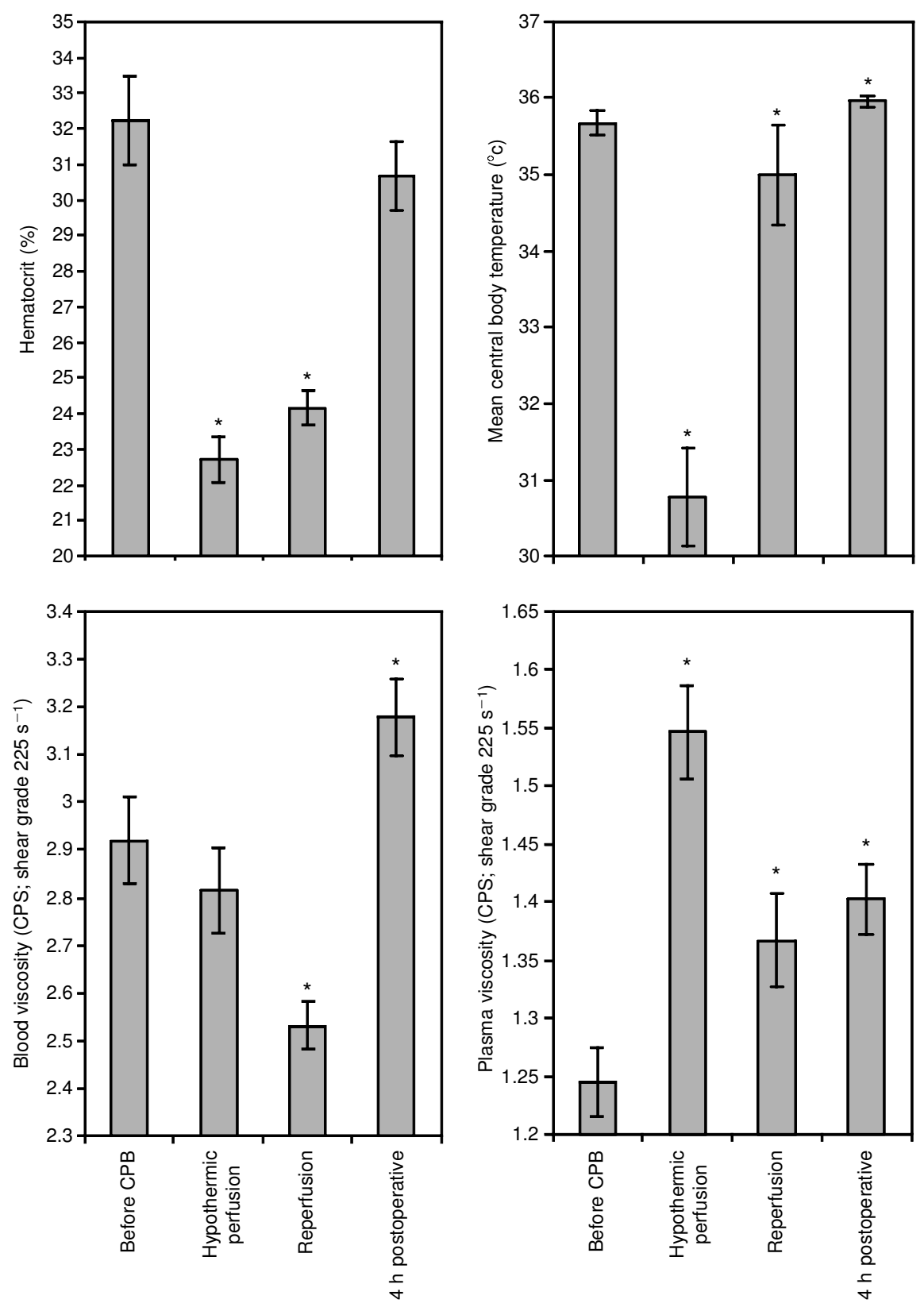

Figure 2.

Data are given as mean \pm SEM. ${ }^{*} p<0.05$ compared to first column. The bars represent the analyses at the intra- and postoperative sample periods during cardiopulmonary bypass. During hypothermic perfusion (second bar in each diag ram), plasma viscosity was elevated (low er right diag ram), while blood viscosity (lower left diag ram) was less elevated due to hemod ilution (upper left diag ram).

Table 2. Cardiopulmonary bypass conditions.

\begin{tabular}{lllll}
\hline & Before CPB & Aortic cross-clamping & Reperfusion & 4 h postoperatively \\
\hline Colloid oncotic pressure $(\mathrm{mmHg})$ & $16.0(9.8-20.1)$ & $\begin{array}{c}15.8(11.6-24.6) \\
184(107-263)\end{array}$ & $\begin{array}{c}16.6(13.1-22.4) \\
201(87-304)\end{array}$ & $19.7(13.3-39.1)$ \\
Mean CPB flow $(\mathrm{ml} / \mathrm{min} \mathrm{kg})$ & $35.8(33.5-37.4)$ & $30.7(18-36.2)^{* \dagger}$ & $36(15-37)^{*}$ & $35.9(35-36.9)$ \\
\hline Central body temperature $\left({ }^{\circ} \mathrm{C}\right)$ & &
\end{tabular}

Data are given as median (minimum-maximum); CPB: cardiopulmonary bypass

functional renal alteration, or meaningful damage. The findings indicating decreased tubular function were only minor, and could not be interpreted as serious ischemic tubular damage. Elevated diuresis during cardiopulmonary bypass in the presence of constant colloid osmotic pressures might be interpreted as a worsened capacity for tubular concentration, or a raised gradient of glomerular filtration. Thus, the observed albuminuria, and the loss of higher molecular weight proteins into the urine, 
Table 3. Correlation of main predictors to blood viscosity at normothermia and hypothermia.

\begin{tabular}{lll}
\hline & $\begin{array}{l}\text { Blood viscosity at normothermia } \\
\text { (prior to cardiopulmonary bypass) }\end{array}$ & $\begin{array}{l}\text { Blood viscosity at } \\
\text { hypothermic perfusion }\end{array}$ \\
\hline Hemoglobin & $\mathbf{r}=\mathbf{0 . 8 0 5}$ & $\mathrm{r}=0.407$ \\
& $\mathbf{p}<\mathbf{0 . 0 0 0 5}$ & $\mathrm{p}=0.012$ \\
Hematocrit & $\mathbf{r}=\mathbf{0 . 8 0 3}$ & $\mathrm{r}=0.403$ \\
& $\mathbf{p}<\mathbf{0 . 0 0 0 5}$ & $\mathrm{p}=0.025$ \\
Plasma viscosity & $\mathrm{r}=0.19$ & $\mathbf{r}=\mathbf{0 . 5 8 9}$ \\
Mean central body temperature & $\mathrm{p}=0.259$ & $\mathbf{p}<\mathbf{0 . 0 0 0 5}$ \\
& $\mathrm{r}=0.118$ & $\mathbf{r}=\mathbf{0 . 7 4 9}$ \\
& $\mathrm{p}=0.494$ & $\mathbf{p}<\mathbf{0 . 0 0 0 5}$ \\
\hline
\end{tabular}

Significant correlations are highlighted

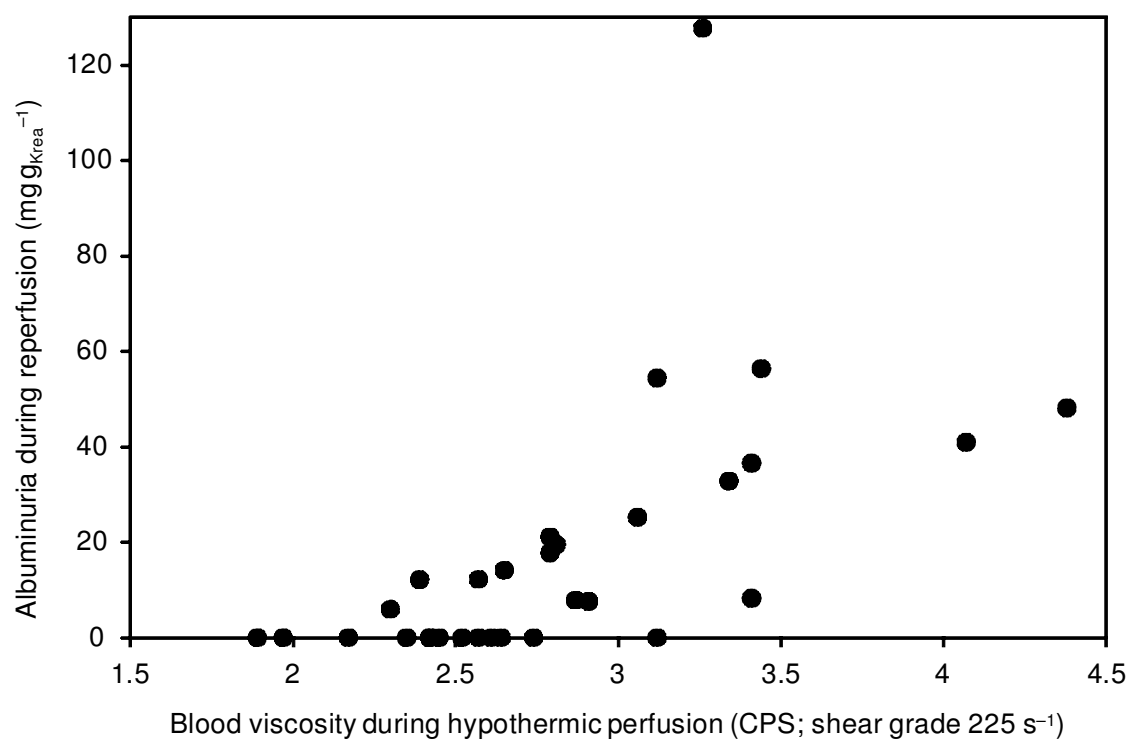

Figure 3.

Correlation of blood viscosity during hyposthermic perfusion and albuminuria during reperfusion: $\quad r=0.705 ; \quad p<0.0005$; $n=34$. might be caused simply by an increased transglomerular filtration gradient, and not by the destruction of the glomerular membrane. ${ }^{6,16,17}$ The quick postoperative normalization of proteinuria further supports the thesis of transitory functional disorder. The elevation of the transglomerular gradient, nonetheless, might be influenced by postglomerular limitations in perfusion. If the capillary blood flow in the postglomerular plexus does not provide enough oxygen to the tubular cells, the kidney perpetuates the perfusion in the postglomerular capillary bed by dilation of the preglomerular capillaries at the expense of an increased filtration gradient. ${ }^{17}$ This would explain the elevated excretion of sodium, and the elevated activity of $\mathrm{N}$-acetyl- $\beta$-Dglucosaminidase, both of which are indicative of tubular alterati ons during cardiopulmonary bypass.

It is known that hemodilution during hypothermia improves the microcirculation, ${ }^{11,12,18}$ while high blood viscosity can lead to capillary occlusion. ${ }^{19}$ Besides all the factors influencing the kidneys during cardiopulmonary bypass, our data showed a statistical correlation between blood viscosity during cardioplegia and albuminuria, as well as between blood viscosity and urinary values of $\mathrm{N}$-acetyl- $\beta$-Dglucosaminidase. The descriptive design of our study does not allow to comment on the causality of this observations. The possibility that improvement of blood viscosity during hypothermic cardioplegia might improve renal function and protection now needs validation in a prospective interventional study. Moreover, the influence of plasma viscosity on blood viscosity during hypothermia should be considered as a means of elevating blood viscosity without changing the hematocrit. ${ }^{20,21}$

\section{Limitations of the study}

Clearly, some surgical procedures are associated with renal dysfunction more than others. It is reasonable to assume, therefore, that there is substantial heterogeneity within the population studied, and that such heterogeneity will attest to the number of factors 
which may influence the kidney. For the same reason, it is difficult to comment on the potential impact of perioperative medication, or the use of nitroprusside, on renal function. As numerous postoperative conditions are associated with postoperative cardiac and renal function, it is advisable not to comment on the question whether intraoperative renal dysfunction as described is a predictor of acute renal failure or the need of dialysis.

\section{Acknowledgements}

We thank Diane Kendall and Tony Derwent for providing editorial assistance in the preparation of the manuscript.

\section{References}

1. Dittrich S, Daehnert I, Vogel M, Stiller B, Haas NA, AlexiMeskishvili V, Lange PE. Peritoneal dialysis after infant open heart surgery: observations in 27 patients. Ann Thorac Surg 1999; 68: 160-163.

2. Asfour B, Bruker B, Kehl HG, Frund S, Scheld HH. Renal insufficiency in neonates after cardiac surgery. Clin Nephrol 1996; 46: 59-63.

3. Frost L, Pedersen RS, Lund O, Hansen OK, Hansen HE. Prognosis and risk factors in acute, dialysis-requiring renal failure after openheart surgery. Scand J Thorac Cardiovasc Surg 1991; 25: 161-166.

4. Mangano CM, Diamondstone LS, Ramsay JG, Aggarwal A, Herskowitz A, Mangano DT. Renal dysfunction after myocardial revascularization: risk factors, adverse outcomes, and hospital resource utilization. The Multicenter Study of Perioperative Ischemia Research Group. Ann Intern Med 1998; 128: 194-203.

5. Ranucci M, Pavesi M, Mazza E, Bertucci C, Frigiola A, Menicanti L, Ditta A, Boncilli A, Conti D. Risk factors for renal dysfunction after coronary surgery: the role of cardiopulmonary bypass technique. Perfusion 1994; 9: 319-326.

6. Pathi VL, Morrison J, MacPhaden A, Martin W, McQuiston AM, Wheatley DJ. Alterations in renal microcirculation during cardiopulmonary bypass. Ann Thorac Surg 1998; 65: 993-998.

7. Undar A, Masai T, Yang SQ, Goddard-Finegold J, Frazier OH, Fraser CD, Jr. Effects of perfusion mode on regional and global organ blood flow in a neonatal piglet model. Ann Thorac Surg 1999; 68: 1336-1342.

8. Remuzzi A, Puntorieri S, Brugnetti B, Bertani T, Remuzzi G. Renoprotective effect of low iron diet and its consequence on glomerular hemodynamics. Kidney Int 1991; 39: 647-652.

9. Garcia DL, Anderson S, Rennke HG, Brenner BM. Anemia lessens and its prevention with recombinant human erythropoietin worsens glomerular injury and hypertension in rats with reduced renal mass. Proc Natl Acad Sci USA 1988; 85: 6142-6146.

10. Undar A, Henderson N, Thurston GB, Masai T, Beyer EA, Frazier $\mathrm{OH}$, Fraser $\mathrm{CD}$, Jr. The effects of pulsatile versus nonpulsatile perfusion on blood viscoelasticity before and after deep hypothermic circulatory arrest in a neonatal piglet model. Artif Organs 1999; 23: 717-721.

11. Dittrich S, Schuth A, Aurich H, von Loeper J, Grosse-Siestrup C, Lange PE. Haemodilution improves organ function during normothermic cardiopulmonary bypass: investigations in isolated perfused pig kidneys. Perfusion 2000; 15: 225-229.

12. Naik SK, Elliott MJ. Ultrafiltration and paediatric cardiopulmonary bypass. Perfusion 1993; 8: 101-112.

13. Dittrich S, Haas NA, Buhrer C, Muller C, Dahnert I, Lange PE. Renal impairment in patients with long-standing cyanotic congenital heart disease. Acta Paediatr 1998; 87: 949-954.

14. Hilberman M, Myers BD, Carrie BJ, Derby G, Jamison RL, Stinson EB. Acute renal failure following cardiac surgery. J Thorac Cardiovasc Surg 1979; 77: 880-888.

15. Dittrich S, Kurschat K, Daehnert I, Vogel M, Mueller C, Lange PE. Cyanotic nephropathy and use of non-ionic contrast agents during cardiac catherization in patients with cyanotic congenital heart disease. Cardiol Young 2000; 10: 8-14.

16. Lodge AJ, Undar A, Daggett CW, Runge TM, Calhoon JH, Ungerleider RM. Regional blood flow during pulsatile cardiopulmonary bypass and after circulatory arrest in an infant model. Ann Thorac Surg 1997; 63: 1243-1250.

17. Simpson LO, Shand BI, Olds RJ. A reappraisal of the influence of blood rheology on glomerular filtration and its role in the pathogenesis of diabetic nephropathy. J Diabet Complications 1987; 1: 137-144.

18. Griepp RB, Ergin MA, Lansman SL, Galla JD, Pogo G. The physiology of hypothermic circulatory arrest. Semin Thorac Cardiovasc Surg 1991; 3: 188-193.

19. Dittrich S, Kurschat K, Daehnert I, Vogel M, Mueller C, AlexiMeskishvili V, Lange PE. Renal function after cardiopulmonary bypass surgery in cyanotic congenital heart disease. Int J Cardiol 2000; 73: 173-179.

20. Cook DJ, Orszulak TA, Daly RC. Minimum hematocrit at differing cardiopulmonary bypass temperatures in $\operatorname{dog} s$. Circulation 1998; 98: II170-174.

21. Shin'oka T, Shum-Tim D, Jonas RA, Lidov HG, Laussen PC, Miura T, du Plessis A. Higher hematocrit improves cerebral outcome after deep hypothermic circulatory arrest. J Thorac Cardiovasc Surg 1996; 112: 1610-1620. 